geography, seven; anthropology and philology, four ; social science and statistics, six; agriculture, eight; engineering and architecture, seven; sanitary science and hygiene, nine; and in mental science and education, four; this section is a very popular one with teachers and others interested in education, and the attendance is usually very large.

The association has made several recommendations to the various Australasian Governments and other authorities, and in the majority of cases these have been sympathetically received, and in certain cases carried out. One of the first recommendations was to the British Admiralty, suggesting that the ocean between Australia, New Zealand, and Tasmania should be named the Tasman Sea; this was agreed to, and the name was at once ordered by the Admiralty to be printed on all charts; previous to this there was some difficulty in speaking of this hitherto nameless part of the Pacific.

The association has also made requests for the reservation of certain areas in Australia and New Zealand for the preservation of the native flora and fauna, some of these have been agreed to; a notable one is the reservation of the island upon which the Tuatara lizard is found. Another smaller reservation was that of a sandstone quarry at Bondi, near Sydney, showing a remarkable columnar or prismatic structure.

Amongst other recommendations made at various meetings to the Australian and New Zealand Governments are the following, some of which have been given effect to :-

(I) That the Federal Government should endeavour to obtain data in the Indian Ocean for long-distance weather forecasting.

(2) The installation at Perth, Western Australia, of a complete set of magnetographs for the continuous registration of magnetic variations; also installations at Brisbane, Port Darwin, and Hobart similar to those at Sydney, Melbourne, \&c. One has recently been installed at Adelaide in response to the association's suggestions.

(3) That the Australian and New Zealand Governments should adopt additional measures to prevent the further extension of tuberculosis amongst cattle and swine.

(4) Recommending the teaching of hygiene and the medical inspection of school children.

(5) That the New Zealand Government should undertake the magnetic survey of the Macquarie Islands now that the survey of the main islands has been completed.

(6) The Australian Governments were urged to take more effective steps for the conservation of forest areas.

The Federal Government was requested in 1902, before determining upon the site of the Federal capital, to appoint a board, consisting of architects, engineers, surveyors, medical and business men, to inquire and report upon the sites proposed; also to reserve a site for a national museum and for the housing of scientific societies and institutions in the proposed Federal capital. In 1898 successful recommendations were made to the New South Wales Government to proceed with the boring at Funafuti.

So that members may come prepared for the discussions. it has been agreed to arrange for the preparation of papers on subjects of which notice had been given at a previous meeting. Arrangements are being made for the preparation and publication of bibliographies which would be beyond the powers of an unaided individual.

Some of the papers of permanent value might usefully be reproduced in English publications, for in spite of the volumes of reports being widely distributed, a paper published at the Antipodes finds very few readers elsewhere, because on receipt of the volumes by an institution they are usually put on the library shelves, and there they remain.

The desirability of inviting the British Association to visit Australia has been considered and warmly advocated at different times since $\mathrm{I} 885$; a reference to the pronosed invitation will be found on p. xxiii of the present volume, in which it was suggested at the Adelaide meeting in 1907 that a sum of $10,000 l$. to $20,000 l$. should be provided to defray part of the travelling expenses of the visitors, and that the invitation should be issued for not earlier than 1913 , so as to leave plenty of time to make proper arrangements.

The permanent offices of the Australian Association are NO. 2096 , VOL. 82 ] in the house of the Royal Society of New South Wales, which has recently provided accommodation for other scientific societies, so as in a small way to afford some of the advantages which Burlington House provides for certain of the English societies; the Sydney societies thus housed have already found much mutual advantage from being under one roof.

A. LIVIRSIDGE.

\section{EPIDEMIC DISEASE AMONG THE NORTH AMERICAN INDIANS.}

IN the Bulletin of the Johns Hopkins Hospital for November Dr. H. U. Williams discusses the origin of epidemic diseases among the North American Indians.

He believes that these American races developed an extremely small number of infectious maladies. Many of the most deadly kind-small-pox, leprosy, bubonic plague, glanders, anthrax, rabies-were the result of the introduction of infection from Europe. With regard to tuberculosis, diphtheria, influenza, gonorrhoea, beri beri, and malaria, the case is more doubtful; but these maladies do not seem to have been noticed among the native tribes by the earlier explorers. The origin of syphilis and yellow fever alone can with some degree of certainty be assigned to American soil. As contributory causes to this immunity from infection, the dispersion of the tribes in isolated camps, and the lack of domestic animals (the horse being connected with glanders, the cow with tuberculosis, and the goat with Malta fever), may have prevented the spread of disease.

Dr. Williams further attempts to identify the serious epidemic which prevailed on the western coast about $1612-20$. When the Puritans appeared on the scene they found this region almost entirely depopulated, and they regarded the epidemic as a dispensation of Providence which had removed the savages to make room for the Europeans. It seems probable that this terrible malady was introduced by foreign settlers. It is very generally supposed to have been an outbreak of small-pox or yellow fever; if this be the case, it is remarkable that the early travellers should not have described it under those names. It is significant that in 1614 that ruffian, Hunt, kidnapped several natives, who were carried to Europe, and after a time those who survived were brought back to their native country. Bubonic plague prevailed in London from 1603 to $16 \mathrm{II}$, and sporadic cases were reported in the following years. The European settlers in America seem to have escaped the disease; and if, as seems most probable, the terrible mortality among the Indians was due to plague, the settlers may have been protected, as in the recent epidemic in India, by the fact that they were cleanlier in their habits and better shod than the native population, and that they were thus less liable to contagion through wounds or insect bites.

\section{OPTICAL ACTIVITY WITH NO ASYMMETRIC} ATOM.

$A \mathrm{~N}$ important paper by Profs. Perkin, Pope and Wallach on optically active substances containing no asymmetric atom appears in the Chemical Society's Journal for November. The substance described is I-methylcyclohexylidene-4-acetic acid, and its structure is represented by the formula<smiles>CCCCCC#CCCCCC(=O)O</smiles>

The carbon atom (I) is linked to two identical chains of atoms, and is therefore not asymmetric. The optical activity of the compound depends on the fact that the plane of the ${ }_{\mathrm{H}}^{\mathrm{CH}_{3}}>\mathrm{C}=$ group is at right angles to the plane of the $=\mathrm{C}$ group, the former being perpendicular to the plane of the hexagonal ring and the latter identical with it; the dissimilarity of the $-\mathrm{H}$ and $-\mathrm{CH}_{3}$ radicles 